\title{
Modeling $\mathrm{CO}_{2}$ electrolysis in solid oxide electrolysis cell
}

\author{
Geetha Narasimhaiah • Vinod M. Janardhanan
}

Received: date / Accepted: date

\begin{abstract}
A modified Butler-Volmer equation for the reduction of $\mathrm{CO}_{2}$ by considering multi-step single electron transfer reactions is presented. Exchange current density formulations free from arbitrary order dependency on the partial pressures of reactants and products are proposed for $\mathrm{Ni}$ and $\mathrm{Pt}$ surfaces. Button cell simulations are performed for $\mathrm{Ni}$ YSZ/YSZ/LSM, Pt-YSZ/YSZ/Pt, and Pt/YSZ/Pt systems using two different electrochemical models and simulation results are compared against experimental observations. The first electrochemical model considers charge transfer reactions occurring at the interface between the electrode and dense electrolyte and the second model considers the charge transfer reactions occurring throughout the thickness of the cermet electrode. Single channel simulations are further performed to asses the $\mathrm{O}_{2}$ production capacity of $\mathrm{CO}_{2}$ electrolysis system.
\end{abstract}

Keywords Electrolysis $\cdot$ SOEC $\cdot$ Kinetics $\cdot$ Electrochemistry

\section{Introduction}

Solid-oxide electrolysis cell (SOEC) is capable of converting carbon dioxide to carbon monoxide and oxygen. Oxygen atom is liberated from $\mathrm{CO}_{2}$ at the cathode electrolyte interface through a combination of thermo-catalytic dissociation and electro-catalysis [1]. This dissociation occurs on catalytic surface forming surface adsorbed $\mathrm{CO}$ that desorbs into the gas-phase. The liberated oxygen atom picks up electrons that reaches the cathode through external circuit and forms an $\mathrm{O}^{2-}$ ion. The $\mathrm{O}^{2-}$ ion is then transported through the electrolyte to the interface between the anode and dense electrolyte where it undergoes oxidation and releases the electron to the anode. Unfortunately, only limited studies are available in the literature, especially for the gas-phase electrolysis of $\mathrm{CO}_{2}$. Electrolysis in SOEC is typically

Geetha Narasimhaiah

Department of Chemical Engineering

Indian Institute of Technology Hyderabad

Vinod M. Janardhanan

Department of Chemical Engineering

Indian Institute of Technology Hyderabad E-mail: vj@iith.ac.in 
carried out in the temperature range of $750-1000{ }^{\circ} \mathrm{C}[2]$.

Tao et al. studied the electrolysis of $\mathrm{CO}_{2}$ at the interface of $\mathrm{Pt} / \mathrm{YSZ}$ using a button cell assembly. They have proposed the following two step single electron transfer model for $\mathrm{CO}_{2}$ electrolysis [3]:

$$
\begin{gathered}
\mathrm{CO}_{2}+\mathrm{e}^{-} \rightleftarrows \mathrm{CO}+\mathrm{O}^{-}, \\
\mathrm{O}^{-}+\mathrm{e}^{-}+\mathrm{V}_{\mathrm{o}}^{\bullet \bullet} \rightleftarrows \mathrm{O}_{\mathrm{o}}^{\times} .
\end{gathered}
$$

Based on their comparison of experimental observation with Bockris model, they concluded the second step as the rate limiting one. In a continuation work they have studied the same process in a Pt-YSZ cermet electrode and found the resulting current density to be higher than that of pure Pt electrode [4]. However, this result is obvious due to the distributed nature of three phase boundary and hence higher overall electrochemical reaction rates in a cermet electrode.

Ebbesen and Mogensen carried out the electrolysis of $\mathrm{CO}_{2}$ at $850^{\circ} \mathrm{C}$ in a planar cross flow cell made up of Ni-YSZ cermet electrode, YSZ electrolyte, and LSM cathode [2]. They in fact have operated an SOFC in the electrolysis mode by applying potentials higher than open circuit potential. Ni has modeled these experiments using a 2D numerical model of the flow channels [5]. Although, the flow channels are modeled in 2D, the concentration loss due to porous media transport is calculated using analytical expression.

In the present work we develop a Butler-Volmer equation based on single electron transfer reaction for the electrolysis of $\mathrm{CO}_{2}$. The model is used to reproduce the experimental observation of Tao et al. [3] and Ebbesen et al.[2]. Additionally, the developed Butler-Volmer equation is used along with a distributed charge transfer model and the results are validated by comparing the model predictions with the experimental observation of Tao et al. reported in [4]. Furthermore, the Butler-Volmer equation is used to analyze isothermal single channel co-flow configuration.

\section{Electrochemical model}

Two different electrochemical charge transfer models are considered in this work. In the first model we assume that the charge transfer occurs only at the interface between dense electrolyte and electrode. This model is explained in section 2.2 and is used to reproduce the experimental observations made by Ebbesen and Mogensen [2] and Tao et. al. [3]. In the second model we assume that the electrochemical charge transfer reaction occurs throughout the thickness of the electrode. This model is explained in section 2.3 and is used to reproduce the experimental observation of Tao et al.[4] for Pt-YSZ cermet electrode. Both models require Butler-Volmer equation in-order to evaluate electrochemical reaction rate at the three-phase interfaces, which is explained in the following section.

\subsection{Butler-Volmer kinetics}

The electrochemical reduction of $\mathrm{CO}_{2}$ on the cathode is assumed to follow reaction steps consisting of sticking reactions, desorption reactions, and charge transfer. The adsorption 
and desorption of $\mathrm{CO}_{2}$ to and from the catalytic surface is given by reaction 3 . Similarly, the adsorption and desorption of $\mathrm{CO}$ is given by 4 . Reactions 5 and 6 represent charge transfer steps involving single electron transfer. Reaction 7 represents the incorporation of $\mathrm{O}^{2-}$ ion into bulk YSZ.

$$
\begin{gathered}
\mathrm{CO}_{2}+(\mathrm{s}) \rightleftarrows \mathrm{CO}_{2}(\mathrm{~s}) \\
\mathrm{CO}+(\mathrm{s}) \rightleftarrows \mathrm{CO}(\mathrm{s}) \\
\mathrm{CO}_{2}+\mathrm{e}^{-}(\mathrm{s})+(\mathrm{YSZ}) \rightleftarrows \mathrm{CO}(\mathrm{s})+\mathrm{O}^{-}(\mathrm{YSZ}) \\
\mathrm{O}^{-}(\mathrm{YSZ})+\mathrm{e}^{-}(\mathrm{s}) \rightleftarrows \mathrm{O}^{2-}(\mathrm{YSZ})+(\mathrm{s}) \\
\mathrm{O}^{2-}(\mathrm{YSZ})+\mathrm{V}_{\mathrm{o}}^{\bullet \bullet} \rightleftarrows \mathrm{O}_{\mathrm{o}}^{\mathrm{x}}(\mathrm{YSZ})+(\mathrm{YSZ})
\end{gathered}
$$

Assuming reaction 6 to be the rate limiting one, the following Butler-Volmer equation is derived for the electrochemical reduction of $\mathrm{CO}_{2}$ :

$$
i=i_{0}\left[\exp \left(\frac{\beta_{6, \mathrm{a}} F \eta_{\mathrm{c}}}{R T}\right)-\exp \left(\frac{-\left(1+\beta_{6, \mathrm{c}}\right) F \eta_{\mathrm{c}}}{R T}\right)\right] .
$$

Here $i$ is the current, $i_{0}$ is the exchange current density, $\beta$ is the charge transfer coefficient, $\eta$ is the activation over potential, $F$ is the Faraday constant, $R$ is the gas constant, and $T$ is the temperature. Unlike general form of Butler-Volmer equation, the cathodic direction of Eq. 8 has $(1+\beta)$ as charge transfer coefficient. The exchange current density $i_{0}$ takes the form

$$
i_{0}=i_{\mathrm{CO}_{2}} \exp \left(\frac{-E_{\mathrm{CO}_{2}}}{R T}\right)\left[\frac{\left(p_{\mathrm{CO}_{2}} / p_{\mathrm{CO}}\right)^{1 / 4}}{1+\left(p_{\mathrm{CO}} / p_{\mathrm{CO}}^{*}\right)+\left(p_{\mathrm{CO}_{2}} / p_{\mathrm{CO}_{2}}^{*}\right)}\right] .
$$

Here $p$ is the partial pressure and $p^{*}$ corresponds to the equilibrium pressure. An Arrhenius expression is used to model the temperature dependence of exchange current density. $E_{\mathrm{CO}_{2}}$ is the activation energy used to model the temperature dependence, and $i_{\mathrm{CO}_{2}}$ is the preexponential factor. By considering the adsorption and desorption reaction of $\mathrm{CO}_{2}$ and $\mathrm{CO}$ at equilibrium $p_{\mathrm{CO}_{2}}^{*}$ and $p_{\mathrm{CO}}^{*}$ takes the form

$$
\begin{gathered}
p_{\mathrm{CO}_{2}}^{*}=\frac{\Gamma}{\gamma_{\mathrm{CO}_{2}}} \sqrt{2 \pi R T W_{\mathrm{CO}_{2}}} k_{\mathrm{d}, \mathrm{CO}_{2}} \exp \left(\frac{-E_{\mathrm{des}, \mathrm{CO}_{2}}}{R T}\right) \\
p_{\mathrm{CO}}^{*}=\frac{\Gamma}{\gamma_{\mathrm{CO}}} \sqrt{2 \pi R T W_{\mathrm{CO}}} k_{\mathrm{d}, \mathrm{CO}} \exp \left(\frac{-E_{\mathrm{des}, \mathrm{CO}}}{R T}\right)
\end{gathered}
$$

In the above equations $\Gamma$ is surface site density, $\gamma$ is the sticking coefficient, $W$ is the molecular weight, and $k_{\mathrm{d}}$ and $E_{\mathrm{des}}$ are respectively the pre-exponential factor and activation energy for desorption reaction. The detailed derivation of equation 8 through 11 is given in the appendix. The parameters for calculating $p^{*}$ are given in Table 4 .

Similar to the cathode side charge transfer, a Butler-Volmer equation is also required for 
the charge transfer reaction occurring on the anode side. Based on the following multi-step electron transfer reactions for $\mathrm{O}^{2-}$ ion oxidation on the anode

$$
\begin{gathered}
\mathrm{O}_{\mathrm{o}}^{\times}(\mathrm{YSZ})+(\mathrm{YSZ}) \rightleftarrows \mathrm{O}^{2-}(\mathrm{YSZ})+\mathrm{V}_{\mathrm{o}}^{\bullet \bullet} \\
\mathrm{O}^{2-}(\mathrm{YSZ})+(\mathrm{s}) \rightleftarrows \mathrm{O}^{-}(\mathrm{YSZ})+\mathrm{e} \\
\mathrm{O}^{-}(\mathrm{YSZ})+(\mathrm{s}) \rightleftarrows \mathrm{O}(\mathrm{s})+\mathrm{e} \\
\mathrm{O}(\mathrm{s})+\mathrm{O}(\mathrm{s}) \rightleftarrows \mathrm{O}_{2}+2(\mathrm{~s}),
\end{gathered}
$$

we have derived a Butler-Volmer equation, which takes the form

$$
i=i_{0}\left[\exp \left(\frac{\left(1+\beta_{\mathrm{a}}\right) F \eta_{\mathrm{a}}}{R T}\right)-\exp \left(\frac{-\beta_{\mathrm{c}} F \eta_{\mathrm{a}}}{R T}\right)\right]
$$

However, the above equation together with Eq. 8 failed to reproduce the experimental observation of Tao et. al. [3] and Ebbesen and Mogensen [2]. Therefore, in this work, for $\mathrm{O}^{2-}$ ion oxidation on the anode side the Butler-Volmer equation and the exchange current density formalism reported in [6] is used. According to [6] the current density is expressed as

$$
i=i_{0}\left[\exp \left(\frac{\beta_{\mathrm{a}} F \eta_{\mathrm{a}}}{R T}\right)-\exp \left(\frac{-\beta_{\mathrm{c}} F \eta_{\mathrm{a}}}{R T}\right)\right],
$$

and $i_{0}$ is defined as

$$
i_{0}=i_{\mathrm{O}_{2}} \exp \left(\frac{-E_{\mathrm{O}_{2}}}{R T}\right)\left[\frac{\left(p_{\mathrm{O}_{2}} / p_{\mathrm{O}_{2}}^{*}\right)^{1 / 4}}{1+\left(p_{\mathrm{O}_{2}} / p_{\mathrm{O}_{2}}^{*}\right)^{1 / 2}}\right] .
$$

$p_{\mathrm{O}_{2}}^{*}$ is defined as

$$
p_{\mathrm{O}_{2}}^{*}=A_{\mathrm{O}_{2}} \exp \left(-E_{\mathrm{des}, \mathrm{O}_{2}} / R T\right)
$$

where

$$
A_{\mathrm{O}_{2}}=\frac{k_{\mathrm{des}, \mathrm{O}_{2}} \Gamma^{2} \sqrt{2 \pi W_{\mathrm{O}_{2}} R T}}{\gamma} \exp \left(\frac{-E_{\mathrm{des}, \mathrm{O}_{2}}}{R T}\right) .
$$

For LSM surface $A_{\mathrm{O}_{2}}=4.9 \times 10^{9} \mathrm{~atm}$ and $E_{\mathrm{des}, \mathrm{O}_{2}}=200 \mathrm{~kJ} \mathrm{~mol}^{-1}[6]$.

\subsection{Charge transfer at dense electrolyte electrode interface}

In this the charge transfer reactions occur only at the interface between electrodes and dense electrolyte. For an electrolysis cell the applied potential is related to the over potentials according to the following relation

$$
E_{\mathrm{cell}}=E_{\mathrm{rev}}+\eta_{\mathrm{ohm}}(i)+\eta_{\mathrm{a}}(i)+\eta_{\mathrm{c}}(i)+\eta_{\text {leak }}(i) .
$$

Here $E_{\text {cell }}$ is the cell potential and $E_{\text {rev }}$ is the reversible (Nernst) potential. $\eta_{\mathrm{c}}$ and $\eta_{\mathrm{a}}$ are respectively the activation overpotential for the cathode and anode. The leakage overpotential $\eta_{\text {leak }}$ is defined as

$$
\eta_{\text {leak }}=\eta_{\text {leak,max }}\left(1-|i| / i_{\text {max }}\right),
$$

where $i_{\max }$ is the maximum current and is a fit parameter. The ohmic overpotential $\eta_{\mathrm{ohm}}$ is defined as

$$
\eta_{\mathrm{ohm}}=\frac{l_{\mathrm{e}}}{\sigma} i
$$


$E_{\mathrm{rev}}$ is calculated according to Nernst equation. The leakage overpotential is required only when the experimentally measured open circuit potential differs from the thermodynamically predicted one. Eq 21 can be solved along with Eqs 8 and 17 to evaluate the current $i$ and overpotentials $\eta_{\mathrm{a}}$ and $\eta_{\mathrm{c}}$ for a given cell voltage. The partial pressures required for the calculation of exchange current densities can be evaluated by solving governing equations describing the transport and reaction of species within the porous media.

\subsection{Distributed charge transfer}

The distributed charge transfer model used in this work is explained comprehensively in [7] and hence only briefly described here. Unlike in the case of non-distributed charge transfer, where the electrochemical reactions occur only at the interface between the dense electrolyte and the electrode, in distributed charge transfer electrochemical reactions occur throughout the thickness of the electrode. Under steady state conditions the charge conservation for electron conducting phase and ion conducting phase is written according to Ohms law as [811]

$$
\frac{\mathrm{d}}{\mathrm{d} y}\left(\sigma_{\mathrm{m}}^{\mathrm{e}} \frac{\mathrm{d} \varphi_{\mathrm{m}}}{\mathrm{d} y}\right)= \pm i A_{\mathrm{tpb}}
$$

In the above equation $\sigma$ and $\varphi$ are respectively the effective conductivity and potential of concerned phases and $A_{\mathrm{tpb}}$ is the three phase boundary area available per unit volume. The choice of sign in Eq. 24 depends on the particular phase in the composite electrode [10]. Bruggmann correlation is used to calculate the effective conductivity [12]:

$$
\sigma_{\mathrm{m}}^{\mathrm{e}}=\phi_{\mathrm{m}}^{3 / 2} \sigma_{\mathrm{m}} .
$$

Here $\phi$ is the volume fraction. The pure phase conductivity for YSZ is taken from [6] and the electronic conductivity for Pt at $1023 \mathrm{~K}$ is $\sigma_{\mathrm{Pt}}=2.7963 \times 10^{6} \mathrm{~S} / \mathrm{cm}$. [13]. Assuming uniform potential throughout the current collectors, the cell voltage can be expressed as difference in potential between the cathode and anode current collectors

$$
E_{\text {cell }}=\varphi_{\mathrm{c}}-\varphi_{\mathrm{a}}
$$

Solution of Eq. 24 requires boundary condition at various interfaces. The transport of ions is continuous throughout the membrane electrode assembly (MEA) structure and hence boundary conditions are required only at the current collectors. Since the current collectors are pure electronic conductors, the ion flux $\varphi_{\text {io }}$ vanish leading to

$$
\frac{\mathrm{d} \varphi_{\mathrm{io}}}{\mathrm{d} y}=0
$$

Unlike ion transport, electron transport is not continuous throughout MEA. Since electrolyte does not conduct electrons, the electron flux $\varphi_{\mathrm{el}}$ vanishes at the dense electrolyte electrode interface leading to

$$
\frac{\mathrm{d} \varphi_{\mathrm{el}}}{\mathrm{d} y}=0
$$

In addition to the dense electrolyte electrode interface, we also require boundary condition at the current collectors. The electrode potential at the cathode current collector is arbitrarily set to zero, which automatically sets the potential of the anode current collector according to Eq. 26 [10]. 
The Faradic current density $i$ appearing in Eq. 24 is calculated according to Eqs. 8 and 17 respectively for the cathode and anode. However, the overpotentials appearing in these equations become the local overpotential defined as

$$
\eta=\varphi_{\mathrm{el}}-\varphi_{\mathrm{io}}-E_{\mathrm{ref}},
$$

where $E_{\text {ref }}$ is the relative potential difference between the electronic and ionic conductors at reference state. By setting the reference state for anode activation overpotential to zero, the reference state for the cathode overpotential becomes the open circuit potential [10]. i.e the above equation can be respectively written for the anode and cathode as

$$
\eta_{\mathrm{a}}=\varphi_{\mathrm{el}}-\varphi_{\mathrm{io}},
$$

and

$$
\eta_{\mathrm{c}}=\varphi_{\mathrm{el}}-\varphi_{\mathrm{io}}-E_{\mathrm{rev}} .
$$

Here $E_{\text {rev }}$ is the reversible (Nernst) potential. For model validation using distributed charge transfer we have considered the experiments performed by Tao et al using Pt-YSZ cermet electrode [4].

\section{Numerical model}

The numerical model used in this work to solve for the button cell and channel configurations is described in a number of previous publications. The solution of button cell model is well described in [14]. The channel model is described in [6]. Modeling of distributed charge transfer is explained in [8,10,7]. An interested reader may also refer [15,17-19] for various aspects of species transport model. Very briefly the button cell model solves reaction diffusion equation for species transport in the electrodes along its thickness. Electrochemical reactions are considered only at the dense electrolyte electrode interface for non distributed charge transfer model and throughout the thickness for distributed charge transfer. Solution of the reaction diffusion equation for species transport requires boundary condition for species concentration at the open electrode surfaces as well as at the dense electrode electrolyte interfaces. At the open electrode surface the species mass fractions are assumed to be the inlet mass fractions. At the dense electrode electrolyte interface the species flux is calculated based on the current density. The equation system is solved using the differential algebraic equation solver LIMEX [20].

\section{Results and discussions}

The electrochemistry model developed for the reduction of $\mathrm{CO}_{2}$ is validated by reproducing the experimental data of Tao et al.[3] and Ebbesen and Mogensen [2]. For the oxidation of $\mathrm{O}^{2-}$ ions the Butler-Volmer expression and the exchange current density formulation developed in [6] is used. The electrochemical system considered by Tao et al. consists of Pt electrodes and YSZ electrolyte. In their experiments air is fed to the anode side and $\mathrm{CO}_{2}$ is fed to the cathode side where it undergoes electrochemical reduction and forms CO. Experiments are reported for three different temperature sets: $1023 \mathrm{~K}, 1073 \mathrm{~K}$, and $1123 \mathrm{~K}$. In order to avoid difficulties associated with the calculation of Nernst potential for $100 \% \mathrm{CO}_{2}$, 
we have considered 3\% CO dilution. The model predictions and its comparison to experiments is shown in Fig. 1. Excellent agreement is observed between the model predictions and experimental observation for all the temperature sets considered. The electrochemical and geometrical model parameters used for the calculations are given in Table 1. The open circuit potential is close to $\sim 0.8 \mathrm{~V}$ and as the temperature increases the absolute value of current density increases for any given potential. Any potential below $\sim 0.8 \mathrm{~V}$ would make the electrolysis cell reverse its operation. i.e the cell would start functioning as a fuel cell. In reproducing these experiments the exchange current density $i_{0}$ and $\beta$ serves as the fit parameters. We initially fit $i_{0}$ for two different temperatures and then evaluate $i_{\mathrm{CO}_{2}}$ and $E_{\mathrm{des}, \mathrm{CO}_{2}}$ or $i_{\mathrm{O}_{2}}$ and $E_{\mathrm{des}, \mathrm{O}_{2}}$ by fitting the $i_{0}$ values to Arrhenius expression. However, by no means $i_{0}$ and $\beta$ given in Table 1 corresponds to their unique values. One may be able to reproduce the same results by using a different set of $i_{0}$ and $\beta$ values. Nevertheless, our effort here is to reproduce the experimental results by maintaining the activation overpotential on anode and cathode side in their realistic ranges.

The activation overpotentials on the anode and cathode side is shown in Fig. 2. The overpotentials are plotted against log values of current density. The left branch corresponds to anode and right branch corresponds to cathode. Although not exact the model predictions are in reasonable range when comparing with the experimental results. The average of experimentally observed maximum overpotential on the anode side is $0.8 \mathrm{~V}$ and that for the cathode side is $0.4 \mathrm{~V}$. The corresponding model predicted value are respectively $0.9 \mathrm{~V}$ and $0.3 \mathrm{~V}$.

The distributed charge transfer model is validated with experimental data of Tao et al.[4] at $1023 \mathrm{~K}$ for Pt-YSZ cermet electrode. The geometrical parameters remains the same as in the previous case with volume fraction of $31 \%$ for Pt and considers $97 \% \mathrm{CO}_{2}$ and $3 \% \mathrm{CO}$. The distributed current density is the ionic current through the dense electrolyte [8]. The model results agree reasonably well with the experimental data for comparision between SOECs with Pt electrode and Pt-YSZ cermet electrode. As shown in Fig. 3, there is threefold increase in current density from $29 \mathrm{~mA} / \mathrm{cm}^{2}$ to $94.3 \mathrm{~mA} / \mathrm{cm}^{2}$ at $1.95 \mathrm{~V}$. The exchange current density parameters are given in Table 2 . The increase in current density is due to the increased TPBs for electrochemical reduction of $\mathrm{CO}_{2}$. During parameter fitting we observed that model is more sensitive to exchange current density and charge transfer coefficient parameters of the oxygen electrode than the $\mathrm{CO}_{2}$ electrode. The variation of ionic and electronic flux along the MEA thickness at $2.0 \mathrm{~V}$ is shown in Fig. 4. Since the electrolyte is a pure ionic conductor, the electronic flux is zero at the dense electrolyte electrode interface and is maximum at the current collectors. On contrary the ionic flux is maximum at the dense electrolyte electrode interface and is zero at the current collectors which are pure electronic conductors. On the oxygen electrode, most of the elctrochemical activity is confined to a very thin layer $\sim 20 \mu \mathrm{m}$ adjacent to the dense electrolyte. Whereas in the case of cathode, i.e, $\mathrm{CO}_{2}$ electrode, the electrochemical activity is distributed throughout the electrode thickness.

The model predictions for the experiments reported by Ebbesen and Mogensen are shown in Fig. 5. These authors have used Ni-YSZ/YSZ/LSM system. The experiments are performed at constant temperature of $1123 \mathrm{~K}$ but for two different compositions; one with $\mathrm{CO}_{2} / \mathrm{CO}: 50 / 50$ and another with $\mathrm{CO}_{2} / \mathrm{CO}: 70 / 30$. Although very good agreement is observed between the model predictions and experimental observations at high operating potential the model slightly under-predicts the current density for $\mathrm{CO}_{2} / \mathrm{CO}: 70 / 30$. The current density increases with increase in concentration of $\mathrm{CO}_{2}$ in the inlet mixture. The electrochemical and 
geometrical parameters used for simulations are listed in Table 3. Since the experiments are done only for one temperature, we do not consider the temperature dependence of exchange current density and Eq. 9 and Eq. 18 respectively reduces to

$$
i_{0}=i_{\mathrm{CO}_{2}}\left[\frac{\left(p_{\mathrm{CO}_{2}} / p_{\mathrm{CO}}\right)^{1 / 4}}{1+\left(p_{\mathrm{CO}} / p_{\mathrm{CO}}^{*}\right)+\left(p_{\mathrm{CO}_{2}} / p_{\mathrm{CO}_{2}}^{*}\right)}\right],
$$

and

$$
i_{0}=i_{\mathrm{O}_{2}}\left[\frac{\left(p_{\mathrm{O}_{2}} / p_{\mathrm{O}_{2}}^{*}\right)^{1 / 4}}{1+\left(p_{\mathrm{O}_{2}} / p_{\mathrm{O}_{2}}^{*}\right)^{1 / 2}}\right] .
$$

It can be noticed from Fig. 5 that for any given temperature the open circuit potential increases with increasing $\mathrm{CO}$ concentration.

Channel simulations are performed after validating the button cell model. Parameters used to simulate the experimental observation of Ebbesen and Mogensen are used to simulate channel flow. Simulations are carried out under isothermal condition of $1123 \mathrm{~K}$ assuming $70 \% \mathrm{CO}_{2}$ and $30 \% \mathrm{CO}$ for the cathode channel inlet and air for anode channel inlet. Both streams are assumed to enter at a velocity of $0.3 \mathrm{~m} \mathrm{~s}^{-1}$. The compositions within the cathode channel and anode channel for a $10 \mathrm{~cm}$ long cell are shown respectively in Fig. 6 and Fig. 7. Two different applied potentials, $1.2 \mathrm{~V}$ and $1.7 \mathrm{~V}$ are considered and the simulations are carried out with exchange current density parameters given in Table 3. Conversion of $\mathrm{CO}_{2}$ reaches maximum towards the exit of the channel for $1.2 \mathrm{~V}$, however, when the applied potential is increased from 1.2 to $1.7 \mathrm{~V}$ early conversion of $\mathrm{CO}_{2}$ and early production of $\mathrm{O}_{2}$ occurs in the channel. In fact for $1.7 \mathrm{~V}, 100 \% \mathrm{CO}_{2}$ conversion is achieved at a distance of $0.08 \mathrm{~m}$ from the leading edge of the reactor. Therefore $100 \%$ conversion can be achieved by increasing the applied potential. As $\mathrm{CO}_{2}$ is converted $\mathrm{O}_{2}$ mole fraction increases in the anode channel. However, Boudouard reaction equilibrium is shifted towards coke formation at $\mathrm{CO}$ mole fractions higher than $95 \%$. Therefore, it is ideal to keep $\mathrm{CO}_{2}$ conversion below $95 \%$ either by adjusting the applied cell potential or by adjusting the residence time. Figure 7 shows the mole fraction of $\mathrm{O}_{2}$ and $\mathrm{N}_{2}$ in the anode flow channel as well as the mass flow rate of $\mathrm{O}_{2}$ along the channel for an applied potential of $1.2 \mathrm{~V}$.

The variation in the current density and reversible potential along the length of the planar cell for the same case is shown in Fig. 8. The current density decreases along the length of the channel because of mixture dilution due to $\mathrm{CO}$ production. However, the dilution has a positive effect on reversible potential and it increases along the channel length. Finally $\mathrm{O}_{2}$ production is one of the main objective of $\mathrm{CO}_{2}$ electrolysis. Based on our model parameters $\sim 100 \mathrm{~m}^{3} \mathrm{O}_{2}$ can be produced in one hr using a $\mathrm{kW}$ stack.

\section{Conclusions}

We have developed a modified Butler-Volmer equation for the reduction of $\mathrm{CO}_{2}$ by considering multi-step single electron transfer reactions. Based on the derivation, exchange current density formulations are proposed for $\mathrm{Ni}$ and $\mathrm{Pt}$ surfaces that are free from arbitrary order dependency on the partial pressures of reactants and products. The derived Butler-Volmer equation together with the Butler-Volmer equation for oxygen charge transfer presented in [6] we have reproduced the experimental observations of Tao et al. [3,4] and Ebbesen 
and Mogensen [2]. The model equations are further used to analyze the behavior of single channel. Generally early $\mathrm{CO}_{2}$ conversion is observed with increasing applied cell potential. The channel length can be reduced by operating the cell at high potentials, which inturn reduces the cost of SOEC setup. It is observed that although it is possible to achieve $100 \%$ conversion its ideal to keep conversion below $95 \%$ due to Boudouard reaction equilibrium. 


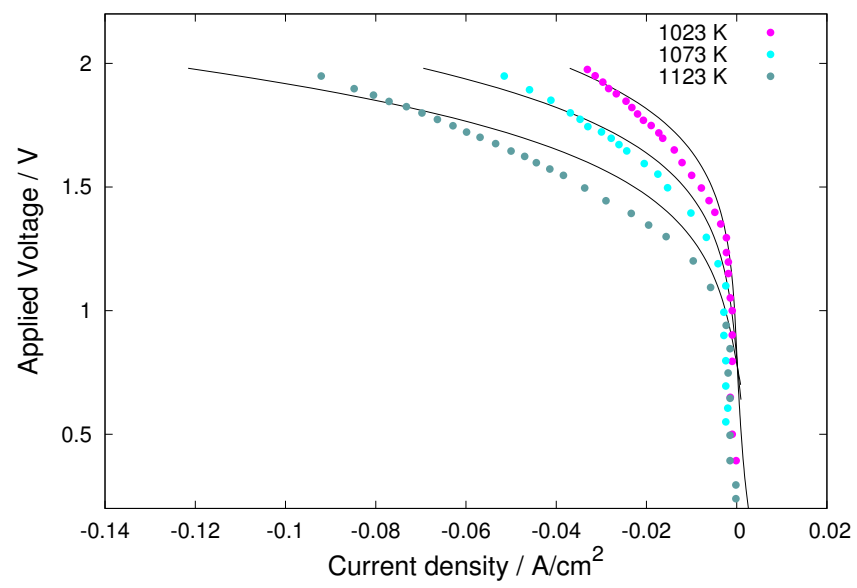

Fig. 1 Comparison of model predictions with the experimental data of Tao et al. [3]. The symbols represent experimental observation and lines represent model predictions.

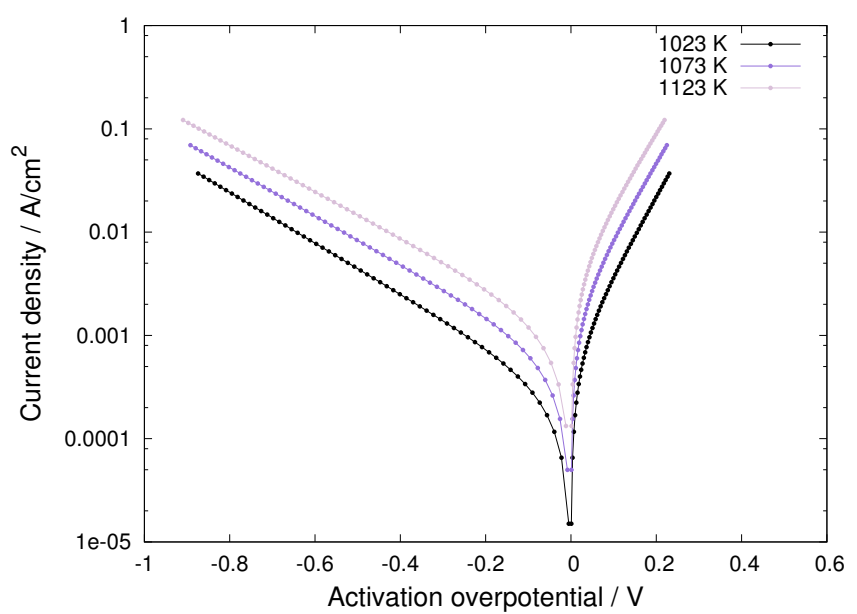

Fig. 2 Model predicted activation overpotentials for the experiments reported by Tao et al. [3]. 


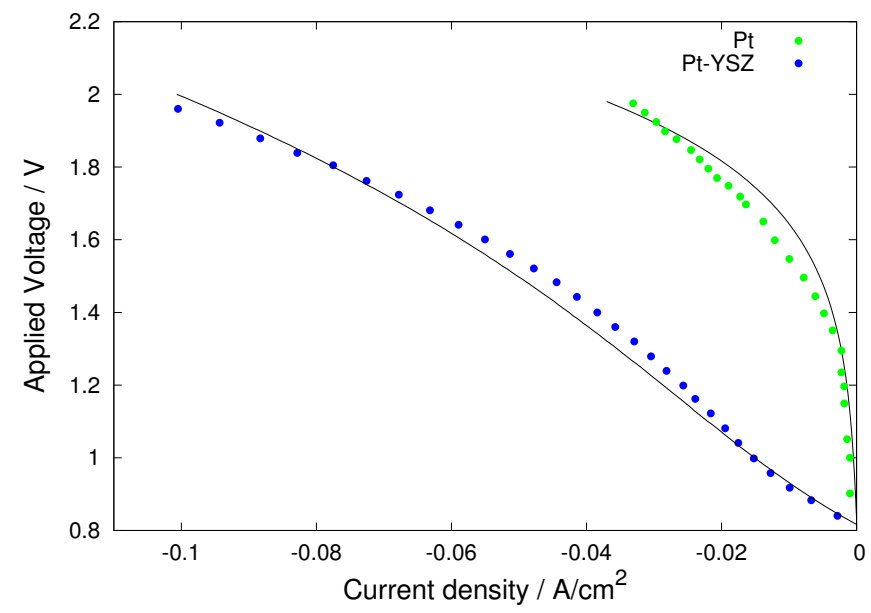

Fig. 3 Comparision of model predictions with experimental data of Tao et al. for SOEC with Pt electrode and Pt-YSZ cermet electrode [4]. The symbols represent experimental observation and straight line represents model prediction.

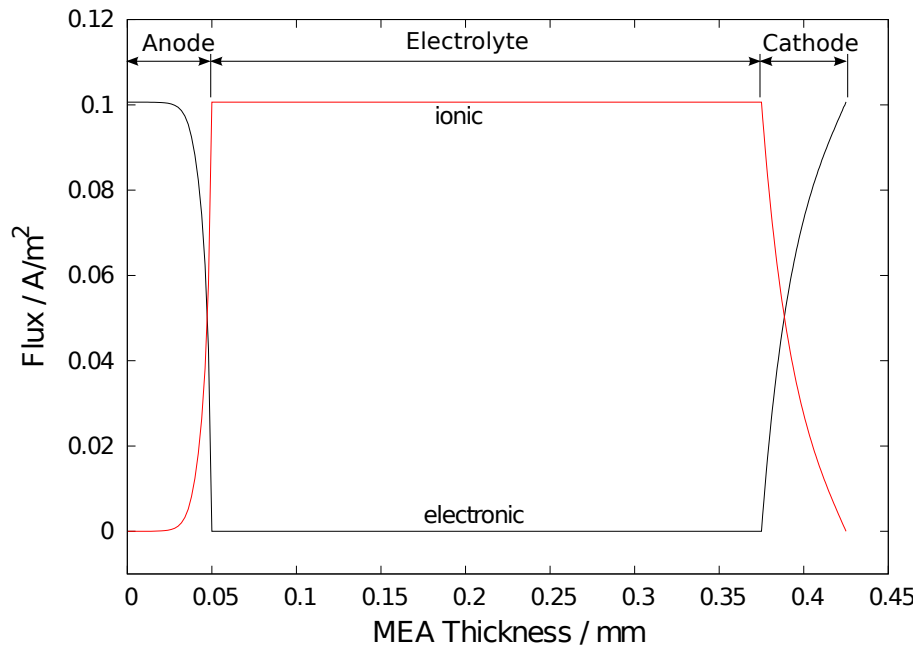

Fig. 4 Ionic flux and electronic flux distribution along MEA thickness at $2.0 \mathrm{~V}$ for the data presented in Fig. 3 


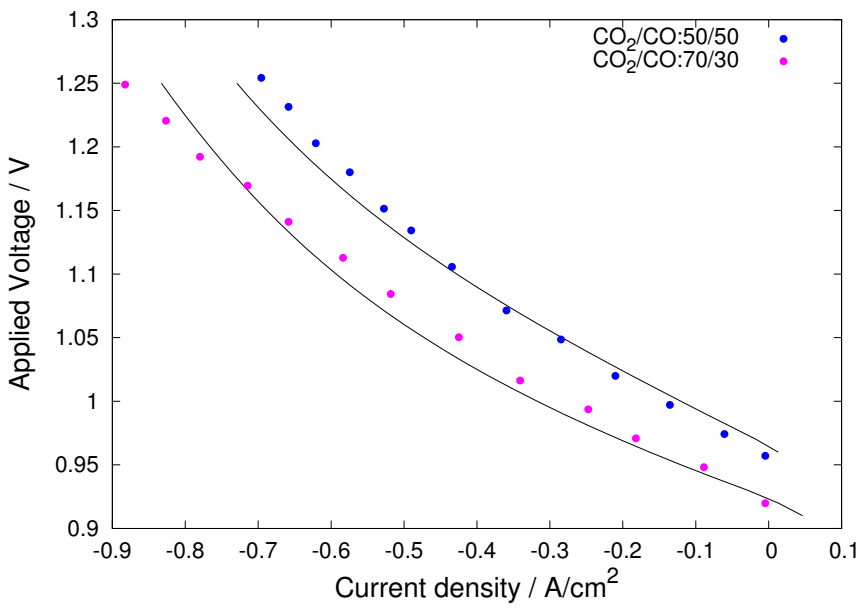

Fig. 5 Comparison of model predictions with the experimental data of Ebbesen and Mogensen [2]. The symbols represent experimental observation and lines represent model predictions.

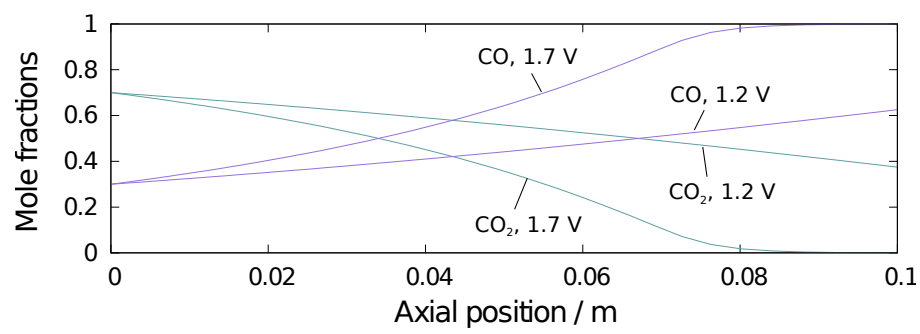

Fig. 6 Mole fraction of $\mathrm{CO}$ and $\mathrm{CO}_{2}$ along the axial position of a planar channel operating at $1123 \mathrm{~K}$. Two different applied potentials are considered $1.2 \mathrm{~V}$ and $1.7 \mathrm{~V}$. The inlet mixture considered for the cathode channel is $70 \% \mathrm{CO}_{2}$ and $30 \% \mathrm{CO}$ entering at $0.3 \mathrm{~m} \mathrm{~s}^{-1}$.

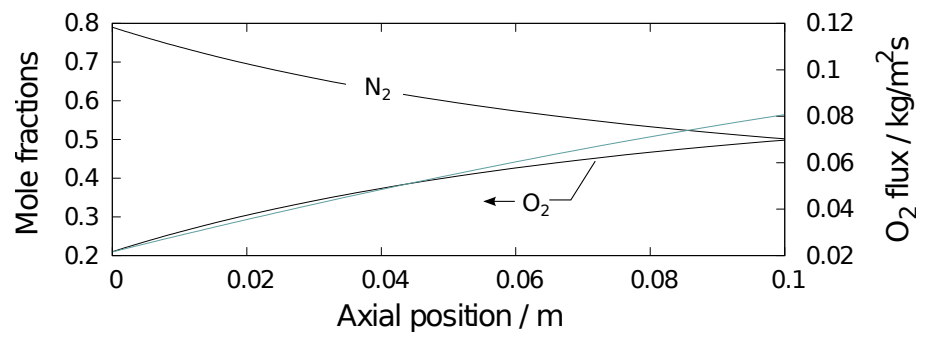

Fig. 7 Mole fraction of $\mathrm{O}_{2}$ and $\mathrm{N}_{2}$ along the axial position of a planar channel operating at $1123 \mathrm{~K}$ and 1.2 $\mathrm{V}$ applied cell potential. The inlet mixture considered for the cathode channel is $70 \% \mathrm{CO}_{2}$ and $30 \% \mathrm{CO}$ and inlet for anode channel is air. Both streams are entering at $0.3 \mathrm{~m} \mathrm{~s}^{-1}$. 


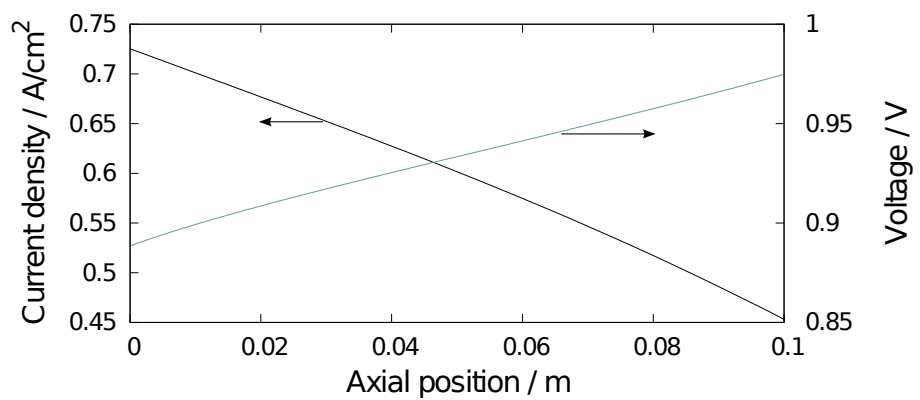

Fig. 8 Current density and reversible (Nernst) potential along the length of a planar cell operating at $1123 \mathrm{~K}$ and $1.2 \mathrm{~V}$ applied cell potential. The inlet mixture considered is $70 \% \mathrm{CO}_{2}$ and $30 \% \mathrm{CO}$ at $0.3 \mathrm{~ms}^{-1}$ 
Table 1 Electrochemical and geometrical parameters used for reproducing data in [3]

\begin{tabular}{|c|c|c|}
\hline Parameter & Value & Unit \\
\hline \multicolumn{3}{|l|}{$\mathrm{O}_{2}$ Electrode } \\
\hline Thickness $\left(l_{\mathrm{a}}\right)$ & 50.00 & $\mu \mathrm{m}$ \\
\hline Average pore radius $\left(r_{\mathrm{p}}\right)$ & 0.50 & $\mu \mathrm{m}$ \\
\hline Average particle diameter $\left(d_{\mathrm{p}}\right)$ & 1.00 & $\mu \mathrm{m}$ \\
\hline Porosity $(\epsilon)$ & 0.45 & \\
\hline Tortuosity $(\tau)$ & 3.00 & \\
\hline Charge transfer coefficient $\left(\beta_{\mathrm{a}}\right)$ & 0.50 & \\
\hline$i_{\mathrm{O}_{2}}$ & 58.87 & $\mathrm{~A} \mathrm{~cm}^{-2}$ \\
\hline$E_{\mathrm{O}_{2}}$ & 87.518 & $\mathrm{~kJ} \mathrm{~mol}^{-1}$ \\
\hline \multicolumn{3}{|l|}{ Electrolyte } \\
\hline Thickness $\left(l_{\mathrm{e}}\right)$ & 325.00 & $\mu \mathrm{m}$ \\
\hline \multicolumn{3}{|l|}{$\mathrm{CO}_{2}$ Electrode } \\
\hline Thickness $\left(l_{\mathrm{a}}\right)$ & 50.00 & $\mu \mathrm{m}$ \\
\hline Average pore radius $\left(r_{\mathrm{p}}\right)$ & 0.50 & $\mu \mathrm{m}$ \\
\hline Average particle diameter $\left(d_{\mathrm{p}}\right)$ & 1.00 & $\mu \mathrm{m}$ \\
\hline Porosity $(\epsilon)$ & 0.45 & \\
\hline Tortuosity $(\tau)$ & 3.00 & \\
\hline Charge transfer coefficient $\left(\beta_{\mathrm{a}}\right)$ & 0.50 & \\
\hline$i_{\mathrm{CO}_{2}}$ & 2884.0 & $\mathrm{~A} \mathrm{~cm}^{-2}$ \\
\hline$E_{\mathrm{CO}_{2}}$ & 132.4 & $\mathrm{~kJ} \mathrm{~mol}^{-1}$ \\
\hline \multicolumn{3}{|l|}{ Leakage } \\
\hline$\eta_{\text {leak,max }}$ & 0.05 & $\mathrm{~V}$ \\
\hline$i_{\max }$ & 1.0 & $\mathrm{~A} \mathrm{~cm}^{-2}$ \\
\hline
\end{tabular}

Table 2 Electrochemical parameters to reproduce experimental data in [4] at $1023 \mathrm{~K}$

\begin{tabular}{l|l|l}
\hline \multicolumn{1}{c|}{ Parameter } & Interface model & Distributed model \\
\hline $\mathbf{O}_{2}$ Electrode & & \\
\hline$i_{\mathrm{O}_{2}}$ & $0.002\left(\mathrm{~A} \mathrm{~cm}^{-2}\right)$ & $160\left(\mathrm{~A} \mathrm{~cm}^{-3}\right)$ \\
$\beta_{\mathrm{a}}$ & 0.5 & 0.2 \\
\hline $\mathbf{C O}_{2}$ Electrode & & \\
\hline$i_{\mathrm{CO}_{2}}$ & $0.0005\left(\mathrm{~A} \mathrm{~cm}^{-2}\right)$ & $30\left(\mathrm{~A} \mathrm{~cm}^{-3}\right)$ \\
$\beta_{\mathrm{a}}$ & 0.5 & 0.7 \\
\hline
\end{tabular}


Table 3 Electrochemical and geometrical parameters used for reproducing data in [2]

\begin{tabular}{l|rl}
\hline Parameter & Value & Unit \\
\hline CO $_{2}$ Electrode & & \\
\hline Thickness $\left(l_{\mathrm{a}}\right)$ & 315.00 & $\mu \mathrm{m}$ \\
Average pore radius $\left(r_{\mathrm{p}}\right)$ & 0.50 & $\mu \mathrm{m}$ \\
Average particle diameter $\left(d_{\mathrm{p}}\right)$ & 1.00 & $\mu \mathrm{m}$ \\
Porosity $(\epsilon)$ & 0.35 & \\
Tortuosity $(\tau)$ & 3.00 & \\
Charge transfer coefficient $\left(\beta_{\mathrm{a}}\right)$ & 0.7 & \\
$i_{\mathrm{CO}_{2}}$ & 3.25 & $\mathrm{~A} \mathrm{~cm}$ \\
\hline Electrolyte & & \\
\hline Thickness $\left(l_{\mathrm{e}}\right)$ & 10.00 & $\mu \mathrm{m}$ \\
\hline $\mathbf{O}_{2}$ Electrode & & \\
\hline Thickness $\left(l_{\mathrm{a}}\right)$ & 20.00 & $\mu \mathrm{m}$ \\
Average pore radius $\left(r_{\mathrm{p}}\right)$ & 0.50 & $\mu \mathrm{m}$ \\
Average particle diameter $\left(d_{\mathrm{p}}\right)$ & 1.00 & $\mu \mathrm{m}$ \\
Porosity $(\epsilon)$ & 0.35 & \\
Tortuosity $(\tau)$ & 3.00 & \\
Charge transfer coefficient $\left(\beta_{\mathrm{a}}\right)$ & 0.10 & \\
$i_{\mathrm{O}_{2}}$ & 1.3 & $\mathrm{~A} \mathrm{~cm}{ }^{-2}$ \\
\hline Leakage & & \\
\hline$\eta_{\text {leak,max }}$ & 0.05 & $\mathrm{~V}$ \\
$i_{\text {max }}$ & 1.00 & $\mathrm{~A} \mathrm{~cm}{ }^{-2}$ \\
\hline
\end{tabular}

Table 4 Parameters used for the calculation of $p_{\mathrm{CO}_{2}}^{*}$ and $p_{\mathrm{CO}}^{*}$

\begin{tabular}{l|l|l|l|l|l}
\hline \multirow{2}{*}{} & \multicolumn{4}{|c}{ Surface } \\
\cline { 2 - 6 } & \multicolumn{2}{|c|}{$\mathrm{Ni}^{a}$} & \multicolumn{3}{c}{$\mathrm{Pt}^{b}$} \\
\hline Parameter & $p_{\mathrm{CO}_{2}}^{*}$ & $p_{\mathrm{CO}}^{*}$ & $p_{\mathrm{CO}_{2}}^{*}$ & $p_{\mathrm{CO}}^{*}$ & $p_{\mathrm{O}_{2}}^{*}$ \\
\hline$\Gamma\left(\mathrm{mol} \mathrm{m}^{-2}\right)$ & $2.6 \times 10^{-5}$ & $2.6 \times 10^{-5}$ & $2.72 \times 10^{-5}$ & $2.72 \times 10^{-5}$ & $2.72 \times 10^{-5}$ \\
$\gamma(-)$ & $1 \times 10^{-5}$ & 0.5 & 0.005 & 0.84 & 0.023 \\
$k_{d}\left(\mathrm{~s}^{-1}\right)$ & $6.447 \times 10^{7}$ & $3.56 \times 10^{11}$ & $1 \times 10^{13}$ & $1 \times 10^{13}$ & $3.7 \times 10^{17 c}$ \\
$E_{\mathrm{des}}\left(\mathrm{kJ} \mathrm{mol}^{-1}\right)$ & 25.98 & 111.27 & 20.5 & 125.5 & 213 \\
\hline
\end{tabular}

a [16]

b $[21,22]$

${ }^{c}$ Units in $\mathrm{m}^{2} \mathrm{~mol}^{-1} \mathrm{~s}^{-1}$ 


\section{Appendix}

\section{Derivation of Butler Volmer equation for $\mathrm{CO}_{2}$ reduction}

Five reaction steps are considered for $\mathrm{CO}_{2}$ reduction on the cathode side as summarized in the electrochemistry section. Out of these five reactions, reaction 6 is considered as rate liming for the derivation of Butler-Volmer equation. When reaction 6 is rate liming the other reactions can be considered to be at a state of equilibrium and the equilibrium constant can be expressed in terms of partial pressures and the surface coverages.

$$
\begin{gathered}
K_{3}=\frac{\theta_{\mathrm{CO}_{2}}}{p_{\mathrm{CO}_{2}} \theta_{\mathrm{s}}} \\
K_{4}=\frac{\theta_{\mathrm{CO}}}{p_{\mathrm{CO}} \theta_{\mathrm{s}}}
\end{gathered}
$$

Similarly the equilibrium constant $K_{7}$ relates the surface coverage of electrolyte surface and that of $\mathrm{O}^{2-}$ ion as:

$$
K_{7}=\frac{\theta_{\mathrm{YSZ}}}{\theta_{\mathrm{O}^{2-}}} .
$$

Since reaction 5 involves transfer of electrons, the rate of the reaction is affected by the potential difference. The rate, which is also equal to the current is expressed as

$$
i=L_{\mathrm{tpb}} F\left[k_{5, \mathrm{a}} \theta_{\mathrm{CO}} \theta_{\mathrm{O}^{-}} \exp \left(\frac{\beta_{5, \mathrm{a}} F E_{\mathrm{c}}}{R T}\right)-k_{5, \mathrm{c}} \theta_{\mathrm{CO}_{2}} \theta_{\mathrm{YSZ}} \exp \left(\frac{-\beta_{5, \mathrm{c}} F E_{\mathrm{c}}}{R T}\right)\right]
$$

Here, $E_{c}$ is the potential difference between the cathode and the dense electrolyte, $k_{5, \mathrm{a}}$ and $k_{5, \mathrm{c}}$ are the thermal rate constants in the anodic and cathodic direction. At equilibrium the above equation leads to

$$
\exp \left(\frac{F E_{\mathrm{c}}}{R T}\right)=\frac{1}{K_{5}} \frac{\theta_{\mathrm{CO}_{2}} \theta_{\mathrm{YSZ}}}{\theta_{\mathrm{CO}} \theta_{\mathrm{O}^{-}}},
$$

where $K_{5}=k_{5, \mathrm{a}} / k_{5, \mathrm{c}}$.

For the rate limiting step 6 the rate of reaction is written as

$$
i=L_{\mathrm{tpb}} F\left[k_{6, \mathrm{a}} \theta_{\mathrm{s}} \theta_{\mathrm{O}^{2-}} \exp \left(\frac{\beta_{6, \mathrm{a}} F E_{c}}{R T}\right)-k_{6, \mathrm{c}} \theta_{\mathrm{s}} \theta_{\mathrm{O}^{-}} \exp \left(\frac{-\beta_{6, \mathrm{c}} F E_{c}}{R T}\right)\right] .
$$

Here $k_{6, \mathrm{a}}$ and $k_{6, \mathrm{c}}$ are the thermal rate constants, $\theta_{\mathrm{O}^{2-}}$ and $\theta_{\mathrm{O}^{-}}$are respectively the surface coverages of $\mathrm{O}^{2-}$ and $\mathrm{O}^{-}$ions and $\theta_{\mathrm{s}}$ is the fraction of free surface. Substituting for $\theta_{\mathrm{O}^{-}}$from Eq. 38 into Eq. 39 leads to

$$
i=L_{\mathrm{tpb}} F k_{6, \mathrm{a}} \theta_{\mathrm{s}} \theta_{\mathrm{O}^{2-}}\left[\exp \left(\frac{\beta_{6, \mathrm{a}} F E_{\mathrm{c}}}{R T}\right)-\frac{k_{6, \mathrm{c}}}{K_{5} k_{6, \mathrm{a}}} \frac{\theta_{\mathrm{CO}_{2}} \theta_{\mathrm{YSZ}}}{\theta_{\mathrm{CO}} \theta_{\mathrm{O}^{2-}}} \exp \left(\frac{-\left(\beta_{6, \mathrm{c}}+1\right) F E_{\mathrm{c}}}{R T}\right)\right] .
$$

At equilibrium, by using the relation $\beta_{6, \mathrm{a}}+\beta_{6, \mathrm{a}}=1$, Eq. 39 leads to

$$
\exp \left(\frac{2 F E_{\mathrm{eq}}}{R T}\right)=\frac{1}{K_{6} K_{5}} \frac{\theta_{\mathrm{CO}_{2}} \theta_{\mathrm{YSZ}}}{\theta_{\mathrm{CO}} \theta_{\mathrm{O}^{2-}}} .
$$

Using Eq. 41 in Eq. 40 gives

$$
i=i_{0}\left[\exp \left(\frac{\beta_{6, \mathrm{a}} F \eta_{\mathrm{c}}}{R T}\right)-\exp \left(\frac{-\left(1+\beta_{6, \mathrm{c}}\right) F \eta_{\mathrm{c}}}{R T}\right)\right],
$$

where

and

$$
\eta_{\mathrm{c}}=E_{\mathrm{c}}-E_{\mathrm{eq}},
$$

$$
i_{0}=k_{6, \mathrm{a}} \theta_{\mathrm{s}} \theta_{\mathrm{O}^{2-}} \exp \left(\frac{\beta_{6, \mathrm{a}} F E^{\mathrm{eq}}}{R T}\right) .
$$


The above equation can be simplified by using Eq. 41, and that leads to

$$
i_{0}=k_{6, \mathrm{a}}\left(K_{5} K_{6}\right)^{-\beta_{6, \mathrm{a}} / 2}\left(\frac{\theta_{\mathrm{CO}_{2}} \theta_{\mathrm{YSZ}}}{\theta_{\mathrm{CO}}}\right)^{\beta_{6, \mathrm{a}} / 2} \theta_{\mathrm{O}^{--}}^{\left(1-\beta_{6, \mathrm{a}} / 2\right)} \theta_{\mathrm{s}}
$$

The surface sites are conserved according to

$$
\theta_{\mathrm{s}}+\theta_{\mathrm{CO}}+\theta_{\mathrm{CO}_{2}}=1
$$

and

$$
\theta_{\mathrm{YSZ}}+\theta_{\mathrm{O}^{2-}}+\theta_{\mathrm{O}^{-}}=1
$$

Using the surface site conservation equations the surface coverage of $\theta_{\mathrm{O}^{2-}}$ can be expressed in terms of surface coverages of $\mathrm{CO}$ and $\mathrm{CO}_{2}$. i.e.,

$$
\theta_{\mathrm{O}^{2-}}=\frac{K_{5} \theta_{\mathrm{CO}}}{K_{7} K_{5} \theta_{\mathrm{CO}}+K_{5} \theta_{\mathrm{CO}}+K_{7} \theta_{\mathrm{CO}_{2}} \exp \left(-F E_{c} / R T\right)} .
$$

Substituting this into Eq.45 and doing algebraic manipulation leads to

$$
i_{0}=k_{6, \mathrm{a}}\left(\frac{K_{5} K_{6}}{K_{7}}\right)^{-\beta_{6, \mathrm{a}} / 2}\left(\frac{\theta_{\mathrm{CO}_{2}}}{\theta_{\mathrm{CO}}}\right)^{\beta_{6, \mathrm{a}} / 2} \theta_{\mathrm{s}} \theta_{\mathrm{O}^{2-}}
$$

$\theta_{\mathrm{S}}$ can be expressed in terms of the partial pressures of $\mathrm{CO}$ and $\mathrm{CO}_{2}$ as

$$
\theta_{\mathrm{s}}=\frac{1}{1+K_{4} p_{\mathrm{CO}}+K_{3} p_{\mathrm{CO}_{2}}}
$$

Assuming $\theta_{\mathrm{O}^{2-}}=1, \beta_{6, \mathrm{a}}=0.5$, replacing all constants with $i_{\mathrm{CO}_{2}}^{*}$, and using Eqs. 34, 35 and 50 in Eq. 49 leads to

$$
i_{0}=i_{\mathrm{CO}_{2}}^{*}\left[\frac{\left(p _ { \mathrm { CO } _ { 2 } / p _ { \mathrm { CO } } ) ^ { 1 / 4 } } \left[1+\left(p_{\mathrm{CO}} / p_{\mathrm{CO}}^{*}\right)+\left(p_{\mathrm{CO}_{2}} / p_{\mathrm{CO}_{2}}^{*}\right)\right.\right.}{.} .\right.
$$

In the above equation $p_{\mathrm{CO}_{2}}^{*}=1 / K_{3}$ and $p_{\mathrm{CO}}^{*}=1 / K_{4} \cdot i_{\mathrm{CO}_{2}}^{*}$ is temperature dependent and is expressed in the Arrhenius form as

$$
i_{\mathrm{CO}_{2}}^{*}=i_{\mathrm{CO}_{2}} \exp \left(-E_{\mathrm{CO}_{2}} / R T\right)
$$

Expressions for $p_{\mathrm{CO}_{2}}^{*}$ and $p_{\mathrm{CO}}^{*}$ are obtained by considering reactions 3 and 4 at equilibrium. From reaction 3 it follows

$$
\gamma \sqrt{\frac{R T}{2 \pi W_{\mathrm{CO} 2}}} \frac{p_{\mathrm{CO}_{2}}}{R T} \theta_{\mathrm{s}}=k_{d} \exp \left(-\frac{E}{R T}\right) \theta_{\mathrm{CO}_{2}} \Gamma
$$

In the above equation $\gamma$ is the sticking coefficient and $\Gamma$ is the site density. Other symbols have their usual meaning. From Eq. $53 p_{\mathrm{CO}_{2}}^{*}$ can be defined as

$$
p_{\mathrm{CO}_{2}}^{*}=p_{\mathrm{CO}_{2}} \frac{\theta_{\mathrm{s}}}{\theta_{\mathrm{CO}_{2}}}=\frac{\Gamma}{\gamma_{\mathrm{CO}_{2}}} \sqrt{2 \pi R T W_{\mathrm{CO}_{2}}} k_{\mathrm{d}_{,} \mathrm{CO}_{2}} \exp \left(\frac{-E_{\mathrm{des}, \mathrm{CO}_{2}}}{R T}\right)
$$

Similarly $p_{\mathrm{CO}}^{*}$ is defined as

$$
p_{\mathrm{CO}}^{*}=p_{\mathrm{CO}} \frac{\theta_{\mathrm{s}}}{\theta_{\mathrm{CO}}}=\frac{\Gamma}{\gamma_{\mathrm{CO}}} \sqrt{2 \pi R T W_{\mathrm{CO}}} k_{\mathrm{d}, \mathrm{CO}} \exp \left(\frac{-E_{\mathrm{des}, \mathrm{CO}}}{R T}\right)
$$

$p_{\mathrm{O}_{2}}^{*}$ is defined as

$$
p_{\mathrm{O}_{2}}^{*}=p_{\mathrm{O}_{2}}\left(\frac{\theta_{\mathrm{s}}}{\theta_{\mathrm{O}}}\right)^{2}=\frac{k_{\mathrm{des}, \mathrm{O}_{2}} \Gamma^{2} \sqrt{2 \pi W_{\mathrm{O}_{2}} R T}}{\gamma} \exp \left(\frac{-E_{\mathrm{des}, \mathrm{O}_{2}}}{R T}\right)
$$

Acknowledgements We acknowledge Prof. Olaf Deutschmann at KIT, Germany for the encouraging discussions. 
Table 5 Nonmenclature

\begin{aligned} \hline$A &$ Area $\left(\mathrm{m}^{2}\right) \\ E &$ Activation energy $\left(\mathrm{J} \mathrm{mol}^{-1}\right)$, Voltage $(\mathrm{V}) \\ F &$ Faraday constant $\left(\mathrm{C} \mathrm{mol}^{-1}\right) \\ i &$ Current density $\left(\mathrm{Acm}^{-2}\right) \\ i_{0} &$ Exchange current density $\left(\mathrm{Acm}^{-2}\right) \\ k_{\mathrm{d}} &$ Pre-exponent $\left(\mathrm{s}^{-1}, \mathrm{~m}^{2} \mathrm{~mol}^{-1} \mathrm{~s}^{-1}\right) \\ l &$ thickness $(\mathrm{m}) \\ p &$ Partial pressure $(\mathrm{Pa}) \\ R &$ Gas constant $\left(\mathrm{J} \mathrm{mol} \mathrm{K}^{-1}\right) \\ T &$ Temperature $(\mathrm{K}) \\ W &$ Molecular weight $\left(\mathrm{kg} \mathrm{mol}^{-1}\right) \\ y &$ Independent coordinate $(\mathrm{m}) \\ \beta &$ Charge transfer coefficient \\ $\gamma &$ Sticking coefficient () \\ $\eta &$ Activation overpotential $(\mathrm{V}) \\ \sigma &$ Conductivity $\left.(\mathrm{S} \mathrm{m})^{-1}\right) \\ \varphi &$ Potential $(\mathrm{V}) \\ \Gamma &$ Surface site density $\left(\mathrm{mol} \mathrm{m}^{-2}\right) \\$ Subscripts & \\ a & Anode \\ $\mathrm{c} &$ Cathode \\ des & Desorption \\ leak & Leakage \\ ohm & Ohmic \\ tpb & Threephase boundary \\ io & Ionic \\ $\mathrm{el} &$ Electronic \\ ref & Reference \\ & \end{aligned}




\section{References}

1. Sridhar KR, Vaniman BT (1997) Oxygen production on Mars using solid oxide electrolysis. Solid State Ionics 93:321-328

2. Ebbesen SD, Mogensen M (2009) Electrolysis of carbon dioxide in Solid Oxide Electrolysis Cells. J Power Sources 193:349-358

3. Tao G, Sridhar KR, Chan CL (2004) Study of carbon dioxide electrolysis at electrode electrolyte interface : Part I . Pt YSZ interface. Solid State Ionics 175:615 - 619

4. Tao G, Sridhar KR, Chan CL (2004) Study of carbon dioxide electrolysis at electrode / electrolyte interface : Part II . Pt-YSZ cermet / YSZ interface. Solid State Ionics 175:621 - 624

5. Ni M (2010) Modeling of a solid oxide electrolysis cell for carbon dioxide electrolysis. Chem Eng J 164:246-254

6. Zhu H, Kee RJ, Janardhanan VM, Deutschmann O, Goodwin DG (2005) Modeling Elementary Heterogeneous Chemistry and Electrochemistry in Solid-Oxide Fuel Cells. J Electrochem Soc 152(12):A2427A2440

7. Janardhanan VM, Deutschmann O (2011) Modeling diffusion limitation in solid-oxide fuel cells. Electrochimica Acta 56(27):9775-9782

8. Zhu H, Kee RJ (2008) Modeling Distributed Charge-Transfer Processes in SOFC Membrane Electrode Assemblies. J Electrochem Soc 155:B715-B729

9. Sunde S (2000) Simulations of Composite Electrodes in Fuel Cells. J Electroceramics 5(2):153-182

10. Shi Y, Cai N, Li C (2007) Numerical modeling of an anode-supported SOFC button cell considering anodic surface diffusion. J Power Sources 164:639-648

11. Costamagna P, Costa P, Antonucci V (1998) Micro-modelling of solid oxide fuel cell electrodes. Electrochim Acta 43(97):375-394

12. Kenney B, Karan K (2004) Mathematical Micro-Model of a Solid Oxide Fuel Cell Composite Cathode. In: Hydrogen and Fuel Cells, pp 1-11

13. Woodman M (1966) The thermal conductivity and electrical resistivity of Platinum. In: Platinum Metals Rev., 10(4):132

14. Zhu H, Kee RJ (2003) A general mathematical model for analyzing the performance of fuel-cell membrane-electrode assemblies. J Power Sources 117:61-74

15. Janardhanan VM, Deutschmann O (2007) Numerical study of mass and heat transport in solid-oxide fuel cells running on humidified methane. Chem Eng Sci 62:5473 - 5486

16. Janardhanan VM, Deutschmann O (2006) CFD analysis of a solid oxide fuel cell with internal reforming : Coupled interactions of transport, heterogeneous catalysis and electrochemical processes. J Power Sources 162:1192-1202

17. Shi Y, Cai N, Li C, Bao C, Croiset E, Qian J, Hu Q, Wang S (2007) Modeling of an anode-supported Ni YSZ|Ni ScSZ|ScSZ|LSM ScSZ multiple layers SOFC cell Part I . Experiments, model development and validation. J Power Sources 172:235-245

18. Zhu H, Kee RJ (2006) Modeling Electrochemical Impedance Spectra in SOFC Button Cells with Internal Methane Reforming. J Electrochem Soc 153:A1765-A1772

19. Janardhanan VM, Heuveline V, Deutschmann O (2007) Performance analysis of a SOFC under direct internal reforming conditions. J Power Sources 172:296-307

20. Dueflhardt P, Hairer E, Zugk J (1987) One step and extrapolation methods for differential-algebraic systems . Numer. Math 51:501-516

21. Deutschmann O, Schmidt R, Behrendt F, Warnatz J (1996) Numerical modeling of catalytic ignition. In: Proceeding of Combustion Institute, pp 1747-1754

22. Chatterjee D, Deutschmann O, Warnatz J (2001) Detailed surface reaction mechanism in a three-way catalyst. Faraday Discussions 119:371 - 384 